Article

\title{
The Relationship between Knowledge Characteristics' Fit and Job Satisfaction and Job Performance: The Mediating Role of Work Engagement
}

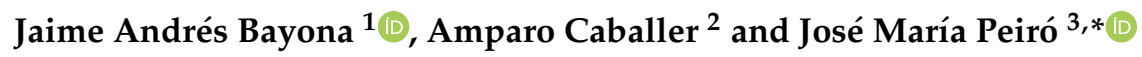 \\ 1 Business Department, Pontificia Universidad Javeriana, 110221 Bogotá, Colombia; \\ jaime.bayona@javeriana.edu.co \\ 2 IDOCAL, Universitat de Valencia, 46010 Valencia, Spain; amparo.caballer@uv.es \\ 3 IDOCAL, Universitat de Valencia \& IVIE, 46010 Valencia, Spain \\ * Correspondence: jose.m.peiro@uv.es
}

Received: 6 February 2020; Accepted: 2 March 2020; Published: 17 March 2020

\begin{abstract}
Knowledge workers are highly valued by organizations, but there is a lack of evidence about the role of work engagement in the satisfaction and performance of these workers. Harmonization and Person-Job Fit theory state that workers who have similar characteristics to those present in the context (i.e., give similar importance to the characteristics present in the context) perform better. The aim of this paper is twofold: to test the congruence effect between five knowledge characteristics and their rated influence on job satisfaction and job performance; and test the mediational role of work engagement between the knowledge characteristics' fit and job performance. Using a time-lagged design, 531 Colombian employees from 20 economic sectors answered questionnaires about work engagement (i.e., UWES-9), knowledge characteristics (i.e., WDQ), importance given to knowledge characteristics, job satisfaction, and job performance. Using polynomial regression, surface response methodology, and ordinary least squares path analyses, we found a congruence effect of the relationship between knowledge characteristics and their levels of importance on job performance in four out of five comparisons (i.e., job complexity, information processing, problem solving, and specialization). In addition, we found that knowledge characteristics' fit indirectly influenced job satisfaction and performance through its effect on work engagement.
\end{abstract}

Keywords: knowledge characteristics; work engagement; job satisfaction; job performance; polynomial regression

\section{Introduction}

The effective management of knowledge workers is crucial for organizational success because these workers are generally responsible for a higher level of productivity in their organizations [1] and key performance indicators [2]. However, these workers are likely to leave organizations if they find that their competences or interests do not match their jobs. To retain these workers, talent management has moved from external to internal motivation, focusing on training in personal variables such as knowledge, skills, abilities, or values, and redesigning contextual variables such as work characteristics [3]. However, despite the central role of these workers and the cost associated with their turnover, there is a lack of evidence about the interaction effect between these personal and contextual variables on job satisfaction and job performance. Person-Job Fit theory states that workers with similar characteristics to those present in the context feel more satisfied and perform better. Our research analyzes the effect of this harmony on job satisfaction and job performance, with work engagement as a mediator. 
In order to be competitive and sustainable in the long run, organizations should focus not only on their financial dimensions, but also on the environmental and social dimensions. Knowledge workers are the key to generating valuable innovations that will lead to financial success and environmental and social outputs. Therefore, in order to retain these workers, it is crucial to pay attention to the precious and scarce resource of the psychological environment [4]. However, unlike in the financial, social, or environmental dimensions, workers pursue two psychological goals: maintaining the generation of value for organizations and, at the same time, securing their own wellbeing and development.

Retaining knowledge workers (also called talented workers or strategic workers) is important in any organization. The positions they occupy are highly strategic, and they generally face high uncertainty in their day-to-day tasks. They are more likely to have more complex jobs, solve more problems, process more information, and need more skills to perform their tasks well. In exchange for performing these complex jobs, these workers want to work in an organization that offers an appropriate wage and working conditions, while allowing them to perform a challenging and interesting job [5]. That is, knowledge workers are interested in harmonic jobs in which they can fulfill their values and achieve higher satisfaction and better performance.

These variables, especially job performance, are not only determined by workers' competence or contextual characteristics, but also by intrinsic motivators such as work engagement $[6,7]$. Work engagement has been defined as a work-related state of mind that enables the worker to focus on the pursuit of organizational objectives. Therefore, we are interested in exploring the interaction patterns between some of the personal and contextual knowledge variables that can improve job satisfaction and job performance, with work engagement as a mediator in this relationship. We build our proposal from the conceptual framework proposed by Christian et al. [8], in which both job characteristics and dispositional characteristics are considered as distal antecedents, work engagement is placed as a mediator, and job performance is considered as an outcome. However, although Christian et al. include job satisfaction in their analyses, it was not placed as an outcome. We think that job satisfaction is a relevant outcome per-se, as "job satisfaction is an evaluative description of job conditions or characteristics" [8] (p. 97).

Recent studies have reviewed the relationship between wellbeing (e.g., job satisfaction) and job performance from various standpoints, such as sustainable wellbeing at work [9], the happy-productive worker model [10], or eudemonic well-being [11]. However, although each of these studies has contributed to better understanding the relationship between well-being and performance, we also know that this relationship is far more complex that we initially thought. The present research contributes to clarifying this relationship, taking into account the psychology of harmony [12] and sustainability [4].

Grounded in these domains, this study makes four main contributions. First, we test the relationship between knowledge characteristics and their importance for employees in order to gain clarity about the role of workers' harmony in today's knowledge economy. This is done taking into account not just the evaluation of knowledge characteristics, but also the importance given to such characteristics by workers, which is a variable that have not been extensively assessed in work design [13]. Second, this relation is tested using polynomial regression and surface analysis, which offer much more information about the interaction between these variables, as it is not limit congruence to a single index of interaction (e.g., $\beta$ ), but instead offers a 3D representation of these interactions with multiple indices of interaction across the variables. Third, we verify the link between knowledge characteristics, work engagement, and job performance, highlighting the influence of intrinsic motivation (i.e., work engagement), and although these relations have been explored before, this study differs from previous efforts as we use the conceptual framework by Christian et al. [8], but include job satisfaction as an additional indicator of well-being. Finally, we respond to the call by Di Fabio and Tsuda [12] for more empirical studies to examine how harmony, if achieved, could contribute to individual and societal well-being. 
Therefore, this research has two objectives: first, to provide empirical evidence from a sample of workers about the influence of harmony (i.e., congruence) between the presence of knowledge characteristics and the importance given to those characteristics on job satisfaction and job performance in a mainly collectivistic society; and second, to test the mediating role of work engagement in this relationship.

\section{Literature Review}

\subsection{Knowledge Characteristics}

Today's knowledge workers have to perform in highly dynamic environments where knowledge generation is the key to organizational performance. In this environment, knowledge characteristics are an essential aspect of work and work design because they reflect the inclusion of a major change in the nature of work, referred to as proactive perspectives. "Proactive perspectives capture the growing importance of employees taking initiative to anticipate and create changes in how work is performed, based on increases in uncertainty and dynamism" [14] (p. 317). Knowledge characteristics reflect the type of knowledge, skills, and abilities an individual has to have in order to do the job. These characteristics include: job complexity, information processing, problem solving, skill variety, and specialization $[15,16]$. Evidence associating each of these knowledge characteristics with job performance is strong. With regard to knowledge characteristics, Humphrey et al. [17] reported a significant Pearson product-moment correlation with job complexity $(r=0.37)$; Lievens and Vlerick [18] reported a positive relationship between knowledge-related work characteristics and safety performance in a Belgian hospital (safety compliance, $r=0.28$; safety participation, $r=0.39$ ); and Wei [19] reported a positive relationship with job complexity in a Chinese organization $(r=0.63)$.

\subsection{Importance of Knowledge Characteristics}

A job with high levels of knowledge characteristics does not necessarily guarantee higher levels of job satisfaction or job performance because doing a job one is not prepared for or interested in leads to low satisfaction, low performance, and eventually turnover. Thus, the importance the worker gives to each knowledge characteristic is also relevant because it offers information about the extent to which $\mathrm{s} /$ he wants to avoid, attain, or retain certain knowledge characteristics. For example, a worker can be placed in a job with high information processing demands (i.e., context), but if $\mathrm{s} /$ he is not happy with these high demands (motivation), this lack of fit will lead to low satisfaction and, eventually, low performance and turnover. A familiar concept in this situation is personal salience, which is defined as " ... the strength with which a person wants to avoid, attain or retain that feature; it does denote the extremity of a personal evaluation in terms of undesirability, or desirability" [20] (p. 394). These judgments of personal salience can often reflect dispositional characteristics. If something is viewed as personally salient, it is by definition more strongly desired, and if it is viewed negatively, there is a stronger desire for avoidance [13]. Evidence for the role of personal salience in the relationship between work characteristics and job performance was tested by Edwards et al. [21], who evaluated the moderating role of the importance of some work features in the relationship between the work context and job performance. However, their results showed little support for this relationship, although it should be taken into account that some of the work characteristics used did not follow any specific work design model.

\subsection{Effects of P-J Fit}

The science of sustainability is centered "on investigating the interaction between human, environmental and engineered systems in order to try to understand the complex factors that contribute to their degradation, to preserve the planet for the future and to promote human well-being" [4] (p. 1). It states that humans and organizations can live in harmony, even though we need to consume natural resources. However, today sustainability includes not only the traditional ecological, social, 
and economic dimensions, but also a new dimension: the psychology of sustainability, which is "focused on the well-being of the person and of the well-being of the environment, and also of the person in the environment, considering different kinds of environments: natural, personal, social, organizational, community, global and cross-cultural environments" [4] (p. 2).

Taking into account that harmonization is a complex process based on balance that uses the metaphor of people tuned as instruments [12], we developed our research from the perspective of a theory based on these same principles in the organizational setting: the Person-Environment Fit theory.

Although researchers have highlighted the importance of both personal and contextual characteristics in fully understanding job performance and job satisfaction [22], studies traditionally report the influence of each of these characteristics separately. This is problematic for two main reasons: (a) the predictors (personal and contextual variables) can interact with each other because their effects on outcome variables are not isolated; and (b) the relationship between predictors and job performance is not necessarily linear [23]. In order to overcome these problems, we based this study on Person-Environment Fit theory, which states that "when characteristics of people and the work environment are similar, aligned or fit together, positive outcomes for individuals such as satisfaction, adjustment, commitment, performance, reduced stress and lower turnover intentions result" [24] (pp. 3-4).

As mentioned above, when there is congruence between the characteristics of the person and the environment, an improvement is expected in the outcome variables. Person-Environment fit meta-analytic evidence has confirmed this, with true score correlations (i.e., $\rho$ ) for person-organization fit and behavioral outcomes such as turnover, $\rho=0.26$, task performance, $\rho=26$, or organizational citizenship behaviors, $\rho=0.21$ [25]. Additionally, for Person-Job fit, significant meta-analytic results were also reported for both job performance $\rho=0.20$ and job satisfaction, $\rho=0.56$ [26].

Based on the evidence presented above, we expect that, when a knowledge characteristic is given similar levels of importance, both job satisfaction and job performance will increase, this is because individuals with goal self-concordance are intrinsically motivated to pursue their goals, and as a result, goals trigger higher performance and satisfaction [27]. However, when a knowledge characteristic has high levels in a job and its importance for the worker is low, we expect that job satisfaction and job performance to be low because workers will have limited interest in dealing with the cognitive demands of their work. On the other hand, if the importance given to a certain knowledge characteristic is high and the knowledge characteristic is low, we expect both job satisfaction and job performance to be low because the activity is central to the worker, but not to his or her work environment. Following this rationale, we expect that the congruence between each of five knowledge characteristics and the importance given to them will be positively related to job satisfaction and job performance, beyond the level of organizational tenure, years of education, and occupational level.

Hypothesis (H1): When knowledge characteristics (i.e., job complexity, information processing, problem solving, skill variety, and specialization) and their importance are both high and congruent, workers will present higher levels of (a) job satisfaction, and (b) job performance.

\subsection{Role of Work Engagement}

Today's organizations are not just interested in improving workers' productivity and retention, but also in building a workplace where their employees feel satisfied and committed because highly talented workers can leave at any time [28]. In this context, companies "must inspire and enable employees to apply their full capabilities to their work" [29] (pp. 4-5). A concept that is highly correlated with both job satisfaction and job performance is work engagement [8], which is defined as a "positive, fulfilling, work-related state of mind that is characterized by vigor, dedication and absorption" [30] (p. 74). "Rather than a momentary and specific state, engagement refers to a more persistent and pervasive affective-cognitive state that is not focused on any particular object, event, individual, or behavior" [30] (p. 74). Meta-analytical evidence [31] suggests that work engagement is 
related to business outcomes such as customer satisfaction $(\rho=0.33)$, profit $(\rho=0.17)$, productivity ( $\rho$ $=0.25)$, turnover $(\rho=-0.30)$, and safety incidents $(\rho=-0.33)$.

This conceptualization of work engagement considers that the most important criteria in the work are the job activities or the work itself [32], which means that the concept is highly influenced by contextual work variables such as work characteristics (e.g., knowledge). These characteristics are considered to be some of the main distal antecedents of work engagement because they can be intrinsically motivating for workers and "will thus affect the extent to which an individual is willing to self-invest their personal energy in their tasks" [8] (p. 98). Meta-analytical evidence [8] suggests that work engagement is in fact related to various knowledge characteristics, showing positive significant correlations with problem solving (.28) and job complexity (.24).

In addition, job performance is determined not only by workers' competence or contextual characteristics, but also by motivation. Some authors have highlighted that a key motivational determinant of job performance is work engagement [6,7] because this work-related state of mind enables the worker to focus on the pursuit of organizational objectives. Therefore, we are interested in exploring the complex interaction patterns between knowledge characteristics, importance, and work engagement.

Considering the meta-analytical evidence presented thus far, we propose that the congruence between knowledge characteristics and their importance would be positively related to work engagement because the notion of fit between the context and the person is the basis of the work engagement concept. As Kahn [33] (p. 694) describes: work engagement is the "harnessing of organization members' selves to their work roles: in engagement, people employ and express themselves physically, cognitively, emotionally and mentally during role performances". According to Kahn, "a dynamic, dialectical relationship exists between the person who drives personal energies (physical, cognitive, emotional, and mental) into his or her work role on the one hand, and the work role that allows the person to express him or herself on the other hand" [32] (p. 12). In addition, previous research has established that work engagement can play a mediating role in the relationship between value congruence and task performance [34]. This relation is especially strong for knowledge characteristics, that are also classified as motivational characteristics [17], which are likely associated with engagement, as employees who have resources that facilitate their job tasks are more apt to invest energy and personal resources in their work roles [8], in turn, "engaged employees report higher levels of well-being and exhibit better performance, that is, better objective as well as subjective perceptions of results at work" [35] (p. 201). Taking these work engagement definitions into account, we can expect that work engagement will be higher when knowledge characteristics' congruence is aligned, as Person-Environment fit theory states. In addition, we also expect that work engagement will partially mediate the effect between knowledge characteristics and both job satisfaction and job performance.

Hypothesis (H2): Work engagement partially mediates the relationship between knowledge characteristics' congruence (i.e., job complexity, information processing, problem solving, skill variety, and specialization) and (a) job satisfaction and (b) job performance.

\section{Materials and Methods}

\subsection{Design, Participants and Procedure}

The sample was obtained in the context of an organizational behavior course at a Colombian business school. Junior-level business administration students analyzed the work of family members or acquaintances (job incumbents) who had worked full time for at least one year, and they administrated the questionnaires to the job incumbents. Each student delivered up to five questionnaires, $85 \%$ of students delivered at least one questionnaire. This particular sampling strategy is used when the goal is to sample a wide range of different jobs $[16,36]$. We used an observational repeated-measures design with two moments; in the first moment, the job incumbent responded to the knowledge characteristic 
items and provided demographic information; in the second moment, the job incumbent responded to the criterion variables (i.e., job satisfaction, job performance, and work engagement). The time-lapse from the first to the second moment was six weeks; the attrition rate for time 2 was $8 \%$. In order to match the questionnaires, a strategy using the job incumbents' parents' initials was used. Workers filled in a paper-and-pencil version of the questionnaires and were informed that all the information provided would be confidential. The ethics review board of Pontificia Universidad Javeriana approved the procedure before the study began.

The sample for this study includes 553 questionnaires. However, 22 questionnaires were rejected due to incomplete information on some of the scales, leaving 531 useful questionnaires that represent 20 out of the 21 economic activities considered in the ISIC classification [37]. The mean age for all participants was 38.9 years ( $S D=11.6$ years), and $52.9 \%$ of the workers were female. In addition, $5.9 \%$ of respondents had only completed a high school/diploma, 58.4\% had completed undergraduate education (university, technical, or technological education), and 31.6\% had completed postgraduate studies or higher. Depending on their job functions, workers self-classified in one of five categories: (a) Operative worker, those who perform basic support activities that require basic technical training $=30(60 \%$ men, age: $M=34.2, S D=11.2$; job tenure: $M=7.9, S D=7.4$ ); (b) Administrative worker, those who work on simple office tasks, such as secretaries or phone operators $=68$ (33.8\% men, age: $M=32.8, S D=11.2$; job tenure: $M=5.9, S D=6.5)$; (c) Technical worker, those who need specific technical training in their duties $=82(40.2 \%$ men, age: $M=37.1, S D=11.4$; job tenure: $M=7.8, S D=8.7)$; (d) Professional worker, those who need a university degree to perform their duties $=234$ ( $46.6 \%$ men, age: $M=39.2$, $S D=11.2$; job tenure: $M=8.4, S D=8.1$ ); and (e) Managers: those with management responsibilities $=107$ (54.2\% men, age: $M=45.1, S D=10.0$; job tenure: $M=10.8, S D=8.8)$. No information was collected from 10 workers (60\% men, age: $M=35.9, S D=10.7$; job tenure: $M=10.3, S D=9.8$ ).

\subsection{Measures}

\subsubsection{Knowledge Characteristics}

We used the knowledge characteristic items from the Work Design Questionnaire developed by Morgeson and Humphrey [16] in its Spanish version by Bayona, Caballer, and Peiró [38]. The questionnaire is a self-report measure that assesses five knowledge characteristics (i.e., job complexity, information processing, problem solving, skill variety, and specialization) through 20 items (four for each knowledge characteristic) rated on a 5-point Likert scale ranging from 1 (strongly disagree) to 5 (strongly agree). A sample item is "The job requires me to analyze a lot of information". Cronbach's alpha for the scale was 0.91 (ranging from 0.72 for problem solving to 0.91 for skill variety).

\subsubsection{Importance of Knowledge Characteristics}

We used a questionnaire developed by Peiró et al. [13] to measure the importance given by the worker to each knowledge characteristic. The item format was based on previous research on the supplementary Person-Environment Fit theory by Cable and Edwards [39] and on personal salience by Warr [20]. For each knowledge characteristic, a corresponding item explores the importance of this characteristic for the job incumbent. The questionnaire asked respondents to rate the importance of five knowledge characteristics using a 5-item scale ranging from 1 (not important at all) to 5 (extremely important). A sample item is "Please indicate how important are the following work characteristic: Information processing (The job requires me to analyze a lot of information)". Cronbach's alpha for this scale was 0.80 .

\subsubsection{Work Engagement}

We used the Spanish version of the Shortened Utrecht Work Engagement Scale (UWES-9) [40]. The UWES-9 is a self-report measure that includes 9 items rated on a 7-point Likert scale ranging from 0 (Never) to 6 (Always, every day). The UWES-9 has one general work engagement factor. A sample 
item is "At my job, I feel strong and vigorous". Cronbach's alpha for the UWES-9 Spanish version was 0.89 .

\subsubsection{Job Performance}

Job performance was measured with a 6-item self-rated performance scale developed by Abramis [41] in its Spanish adaptation reported by Sora-Miana, González-Morales, Caballer, and Peiró [42]. This scale asked respondents to think about their previous week at work and rate how well they performed on six tasks, namely: decision-making, performing without making mistakes, goal attainment, effort, taking initiatives, and taking responsibility. Five response categories were used, ranging from 1 (very badly) to 5 (very well). Some of the items are "1. Making decisions"; "2. Working without making mistakes"; "3. Dedication to his or her work"; "4. Meeting his or her objectives"; "5. Taking initiative"; "6. Accepting responsibility". Cronbach's alpha for the Spanish version of this scale was 0.83 .

\subsubsection{Job Satisfaction}

Job satisfaction was measured with the 4-item job satisfaction scale reported by Price [43] in its Spanish version used by Isaksson [44]. The scale uses a 5-point Likert scale ranging from 1 (nothing important) to 5 (extremely important). This scale asks respondents to rate their job satisfaction based on intrinsic components such as enjoyment, enthusiasm, or boredom. A sample item is "I enjoy my job". For the Spanish version, Cronbach's alpha $=0.81$.

\subsection{Analyses}

To test H1 (a and b), we used polynomial regression analysis and surface response methodology, which have three different stages. The first stage is the calculation of a regression equation that includes five predictors for the outcome variable. For job performance, the regression equation was as follows:

$$
J P=b_{0}+b_{1} \text { Controls }+b_{2} K C+b_{3} I M P+b_{4} K C^{2}+b_{5} K C \times I M P+b_{6} I M P^{2}+e
$$

where $J P$ represents job performance, $b_{1}$ Controls represents control variables (i.e., education, organizational tenure, occupational level, and age), $b_{2} \mathrm{KC}$ represents a knowledge characteristic, $b_{3} I M P$ represents the importance of a knowledge characteristic, $b_{4} K C^{2}$ represents a quadratic term formed by squaring a certain knowledge characteristic, $b_{5} K C \times I M P$ represents an interaction term formed by multiplying a knowledge characteristic by the importance given to this knowledge characteristic, $b_{6} I M P^{2}$ represents a second quadratic term formed by squaring the importance of a knowledge characteristic, and, finally, $e$ represents an error term. Before constructing the quadratic and cross-product terms, knowledge characteristics and importance were centered at the midpoints of their respective scales $[45,46]$.

The second stage is the calculation of parameters and the depiction of a tridimensional graphic. The first two parameters refer to the slope $(b 1+b 2)$ and curvature $(b 3+b 4+b 5)$ of a line of perfect congruence along which knowledge characteristics and importance values are equal in magnitude (KC = IMP); in Figure 1 (an idealized perfect congruence representation), the congruence line comes from the coordinates $\mathrm{x}=-2.5, \mathrm{y}=-2.5$ to $\mathrm{x}=2.5, \mathrm{y}=2.5$. For example, a positive slope $(\mathrm{b} 1+\mathrm{b} 2)$ on the line of perfect congruence would indicate that an outcome increases as both the knowledge characteristic and its importance increase. A positive curvature (b3 $+\mathrm{b} 4+\mathrm{b} 5)$ would indicate a convex (upward curving) surface, whereas a negative curvature would indicate a concave (downward curving) surface (i.e., the outcome could increase or decrease more sharply as both the knowledge characteristic and its importance become lower or higher from some point). The second set of parameters refers to the slope $(b 1-b 2)$ and curvature (b3 - b4 + b5) of a line of perfect incongruence along which the knowledge characteristic and importance values are opposite in magnitude (WC $=-\mathrm{IWC}$ ); in Figure 1, the incongruence line comes from the coordinates $\mathrm{x}=-2.5, \mathrm{y}=2.5$ to $\mathrm{x}=2.5, \mathrm{y}=-2.5$. 
Results from equation 1 and the set of parameters are used to determine whether the coefficients for knowledge characteristic and importance signified a value congruence effect. These coefficients were used to plot three-dimensional surfaces on which knowledge characteristic and importance values were perpendicular horizontal axes, and job performance was the vertical axis.

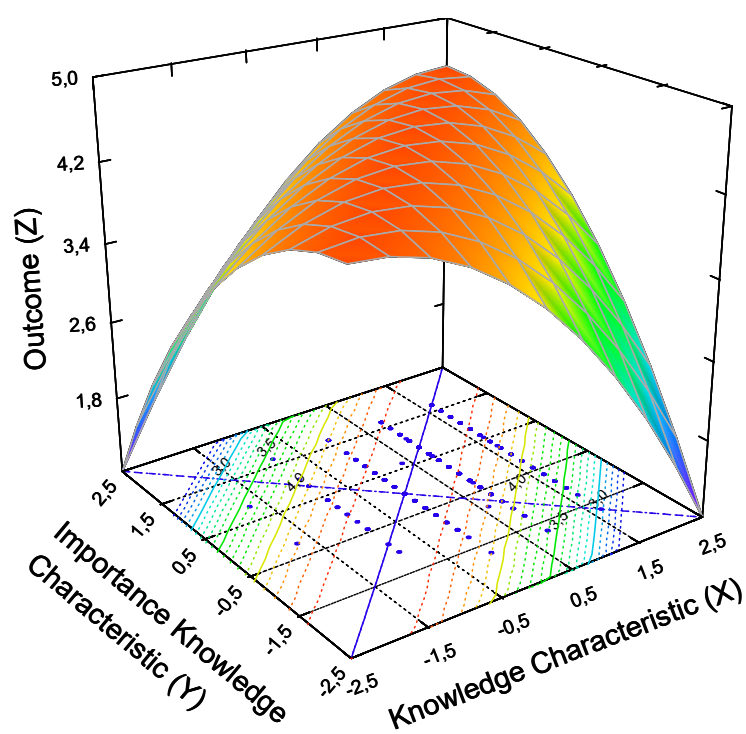

Figure 1. Hypothetical surface representing a congruence effect of knowledge characteristics and importance on an outcome.

In the third stage, we interpreted the results of the parameters to assess whether they support H1. In order to affirm that an increase in knowledge characteristic-importance congruence leads to higher job performance or job satisfaction, two conditions must be met. First, the slope of the congruence line should be positive and significant (i.e., the quantity a1). Second, the curvature of the congruence line should not be significant (i.e., the quantity a2). In addition, although not mandatory, it is preferable that the slope and curvature of the line of incongruence is non-significant (i.e., the quantities a 3 and a4). To test these conditions, we used both linear combinations of regression coefficients and nonlinear combinations of regression coefficients, which were tested using 10,000 bootstrap samples, using the resulting estimates to construct bias-corrected confidence intervals.

H2 was tested with mediation analyses using ordinary least squares path analyses for each knowledge characteristic. For job performance, we performed five different path analyses for each knowledge characteristic: Step 1 (knowledge characteristic $\rightarrow$ work engagement), Step 2 (work engagement $\rightarrow$ job performance), direct effect (knowledge characteristic $\rightarrow$ job performance), indirect effect (knowledge characteristic $\rightarrow$ work engagement $\rightarrow$ job performance), and total effect (direct effect + indirect effect $\rightarrow$ job performance). We performed the same procedure to test job satisfaction. To perform these analyses, we used PROCESS syntax for SPSS (version 2.16) for all the required calculations [47]. In order to conduct these analyses, we transformed the five original terms from equation 1 into a block variable: "A block variable is a weighted linear composite of the variables that constitute the block, in which the weights are the estimated regression coefficients for the variables in the block" [46] (p. 660). The path coefficients obtained from these procedures were used to assess the direct, indirect, and total effects associated with our model, allowing us to determine the extent to which work engagement carried the effects of knowledge characteristic values on job satisfaction or job performance.

Common method bias: Because all of our variables were provided by the same job incumbent, in order to test for common variance effects on our results, we carried out a common latent factor test [48] in which we tested an unconstrained model and a zero-constrained model. 


\section{Results}

In Table 1, we report the means, standard deviations, correlations, and reliability estimates (Cronbach's alpha). The variables' means and standard deviations indicated good dispersion and little evidence of floor or ceiling effects. The correlations between knowledge characteristics and importance were moderate (mean $r=0.29$ ). Work engagement and job performance also presented medium levels of correlation with these variables. As expected, education (mean $r=0.30$ ) and occupational level (mean $r=0.38$ ) presented high correlations with knowledge characteristics. A confirmatory factor analysis of the 44 items representing the 13 constructs listed in Table 1 indicated a good fit, as evidenced by $\chi^{2} / d f=1.86, \mathrm{CFI}=0.95, \mathrm{SRMR}=0.05$ and $\mathrm{RMSEA}=0.04$. Taken together, the evidence indicates that the measures were suitable for our study. Common latent factor test results indicated that the unconstrained and zero constrained models were equal (i.e., $p>0.05$ ); therefore, we could not detect any specific response bias affecting our assessment model [49].

We present the results for $\mathrm{H} 1$ in Table 2. The inclusion of control variables shows that only the occupational level presents significant values for three of the five knowledge characteristics for job performance, and for all the knowledge characteristics for job satisfaction. H1a predicted that job satisfaction would increase as knowledge characteristics and importance increased in congruence. For four of the five knowledge characteristics, this pattern was present because the slope in the line of congruence was positive (a1), and its curvature was non-significant (a2): Information processing: a1 $=0.31(p<0.01), \mathrm{a} 2=-0.08(p=$ n.s. $)$; problem solving: a1 =0.19 $(p<0.05), \mathrm{a} 2=0.04(p=\mathrm{n} . \mathrm{s}$. $)$; skill variety: $\mathrm{a} 1=0.26(p<0.01)$, a2 $=-0.03(p=$ n.s. $)$, and specialization: $\mathrm{a} 1=0.27(p<0.01)$, a2 $=-0.08$ ( $p=$ n.s.). However, for job complexity, although the first condition was present: $\mathrm{a} 1=0.37$ $(p<0.01)$, the curvature of the congruence line was negative and significant: $\mathrm{a} 2=-0.14(p<0.05)$. This result implies that when the importance given to job complexity is low, job satisfaction is also low, independent of the level of job complexity present in the job. However, when the importance is higher, job satisfaction is also higher (Figure 2a). Overall, these results fully support H1a (with the caveat for the pattern found for skill variety). A graphical depiction of these interactions is presented in Figure 2.

In relation to the incongruence line (Table 2, KC =-IMP line), we found that for job complexity and specialization, the slopes present significant values (a1), showing that job satisfaction is higher in a situation of incongruence when job complexity or specialization is low but its levels of importance are higher (Figure 2a,e).

$\mathrm{H} 1 \mathrm{~b}$ predicted that job performance increases as knowledge characteristics and importance increase in congruence. For four of the five knowledge characteristics, this pattern was present (Table 2) because the slope in the line of congruence was positive (a1), and its curvature was non-significant (a2). Job complexity: a1 $=0.19(p<0.01)$, a2 = $0.01(p=$ n.s. $)$; information processing: a1 $=0.31(p<0.01)$, a2 $=-0.03$ ( $p=$ n.s.); problem solving: $\mathrm{a} 1=0.17(p<0.01), \mathrm{a} 2=0.04(p=$ n.s. $)$; and specialization: $\mathrm{a} 1=0.21(p<0.01), \mathrm{a} 2=-0.00(p=$ n.s.). However, for skill variety, although the first condition was present: $\mathrm{a} 1=0.09(p<0.10)$, the curvature of the congruence line was positive and significant: $\mathrm{a} 2=0.10$ $(p<0.01)$; this result implies that when skill variety and its level of importance are valued at both lower and higher levels, job performance also shows higher values. As Figure $3 \mathrm{~d}$ reveals, although at lower values there is an improvement in job performance, the most improvement in job performance is present when both skill variety and its importance are at their highest. Overall, these results fully support $\mathrm{H} 1 \mathrm{~b}$ (with the caveat for the pattern found for skill variety). A graphical depiction of these interactions is presented in Figure 3. 
Table 1. Descriptive statistics.

\begin{tabular}{|c|c|c|c|c|c|c|c|c|c|c|c|c|c|c|c|c|c|c|}
\hline Variable & $\mathbf{M}$ & SD & 1 & 2 & 3 & 4 & 5 & 6 & 7 & 8 & 9 & 10 & 11 & 12 & 13 & 14 & 15 & 16 \\
\hline \multicolumn{19}{|l|}{ Knowledge Characteristics } \\
\hline 1. Job Complexity & 3.55 & 0.89 & $(0.84)$ & & & & & & & & & & & & & & & \\
\hline 2. Information Processing & 4.17 & 0.73 & 0.38 ** & $(0.85)$ & & & & & & & & & & & & & & \\
\hline 3. Problem Solving & 3.68 & 0.79 & 0.20 ** & $0.57^{* *}$ & $(0.72)$ & & & & & & & & & & & & & \\
\hline 4. Skill Variety & 4.00 & 0.77 & $0.27^{* *}$ & $0.62^{* *}$ & $0.62 * *$ & $(0.91)$ & & & & & & & & & & & & \\
\hline 5. Specialization & 3.76 & 0.84 & 0.22 ** & $0.52 * *$ & $0.45^{* *}$ & $0.58^{* *}$ & $(0.87)$ & & & & & & & & & & & \\
\hline \multicolumn{19}{|l|}{ Importance Knowledge characteristics } \\
\hline 6. Importance job complexity & 4.00 & 0.82 & $0.16 * *$ & $0.31^{* *}$ & $0.29 * *$ & $0.37 * *$ & 0.32 ** & $(0.80)^{\mathrm{a}}$ & & & & & & & & & & \\
\hline 7. Importance information processing & 3.98 & 0.88 & $0.14^{* *}$ & $0.38^{* *}$ & $0.28 * *$ & $0.34 * *$ & 0.32 ** & $0.57^{* *}$ & & & & & & & & & & \\
\hline 8. Importance problem solving & 3.90 & 0.95 & 0.15 ** & $0.28^{* *}$ & $0.27^{* *}$ & $0.28 * *$ & $0.19^{* *}$ & $0.39 * *$ & $0.42^{* *}$ & & & & & & & & & \\
\hline 9. Importance skill variety & 4.12 & 0.83 & 0.14 ** & $0.29^{* *}$ & $0.32 * *$ & 0.40 ** & $0.29 * *$ & $0.46^{* *}$ & $0.37^{* *}$ & $0.36 * *$ & & & & & & & & \\
\hline \multicolumn{18}{|l|}{ Mediator } & \\
\hline $\begin{array}{l}\text { 11. Work engagement } \\
\text { Outcomes }\end{array}$ & 4.90 & 0.82 & -0.01 & $0.22^{* *}$ & $0.19 * *$ & $0.20 * *$ & $0.17^{* *}$ & $0.23 * *$ & $0.25 * *$ & $0.12 * *$ & $0.23^{* *}$ & $0.26^{* *}$ & $(0.89)$ & & & & & \\
\hline 12. Job performance & 4.21 & 0.50 & 0.12 ** & $0.29 * *$ & 0.25 ** & $0.32 * *$ & 0.28 ** & $0.33 * *$ & $0.30 * *$ & $0.25 * *$ & 0.32 ** & $0.32 * *$ & $0.49^{* *}$ & $(0.83)$ & & & & \\
\hline 13. Job satisfaction & 4.22 & 0.76 & 0.07 & 0.15 ** & $0.13^{* *}$ & $0.19^{* *}$ & $0.16^{* *}$ & $0.24^{* *}$ & $0.21 * *$ & $0.14^{* *}$ & $0.20^{* *}$ & $0.25 * *$ & $0.69^{* *}$ & $0.42^{* *}$ & $(0.83)$ & & & \\
\hline \multicolumn{19}{|l|}{ Controls } \\
\hline 14. Education & 5.05 & 1.27 & $0.29 * *$ & $0.38^{* *}$ & $0.21 * *$ & $0.33^{* *}$ & $0.31^{* *}$ & $0.17 * *$ & $0.18^{* *}$ & $0.21 * *$ & $0.21^{* *}$ & $0.26^{* *}$ & 0.08 & $0.14 * *$ & 0.03 & & & \\
\hline 15. Organizational tenure & 8.46 & 8.26 & 0.03 & 0.08 & 0.03 & 0.06 & 0.07 & $0.14 * *$ & 0.08 & 0.05 & 0.12 ** & $0.16^{* *}$ & $0.14^{* *}$ & $0.13 * *$ & $0.13^{* *}$ & $0.09 *$ & & \\
\hline 16. Occupational level & 3.61 & 1.12 & $0.37 * *$ & $0.46^{* *}$ & $0.32 * *$ & $0.40 * *$ & $0.37^{* *}$ & $0.23 * *$ & $0.26^{* *}$ & $0.23 * *$ & 0.25 ** & $0.36^{* *}$ & 0.20 ** & $0.23 * *$ & $0.24 * *$ & $0.54^{* *}$ & 0.15 ** & \\
\hline 17. Age & 38.91 & 11.59 & $0.09 *$ & $0.14^{* *}$ & 0.07 & $0.12 * *$ & $0.15^{* *}$ & $0.14^{* *}$ & $0.10 *$ & 0.05 & $0.09 *$ & $0.19^{* *}$ & $0.19^{* *}$ & $0.18^{* *}$ & $0.19^{* *}$ & $0.19^{* *}$ & 0.60 ** & 0.31 ** \\
\hline
\end{tabular}

$\mathrm{N}=531 .{ }^{*} p<0.05 .{ }^{* *} p<0.01$. Cronbach's alphas for each variable are in parentheses. ${ }^{\text {a }}$ This alpha corresponds to the five importance variables.

Table 2. Polynomial Regression Equation Results for Job satisfaction and Job performance.

\begin{tabular}{|c|c|c|c|c|c|c|c|c|c|c|c|c|c|c|c|c|c|}
\hline \multirow[b]{2}{*}{ Outcome } & \multirow[b]{2}{*}{ Dimension } & \multirow{2}{*}{$\begin{array}{c}\text { Constant } \\
\text { (b0) }\end{array}$} & \multicolumn{4}{|c|}{ Controls } & \multirow[b]{2}{*}{$\begin{array}{l}\text { KC } \\
\text { (b1) }\end{array}$} & \multirow{2}{*}{$\begin{array}{l}\text { IMP } \\
\text { (b2) }\end{array}$} & \multirow{2}{*}{$\begin{array}{l}\mathrm{KC}^{2} \\
(\mathrm{~b} 3)\end{array}$} & \multirow{2}{*}{$\begin{array}{l}\text { KC } \times \\
\text { IMP } \\
\text { (b4) }\end{array}$} & \multirow{2}{*}{$\begin{array}{l}\text { IMP }^{2} \\
\text { (b5) }\end{array}$} & \multicolumn{2}{|c|}{$\mathrm{KC}=\mathrm{IMP}$ Line } & \multicolumn{2}{|c|}{$\mathrm{KC}=-\mathrm{IMP}$ Line } & \multirow[b]{2}{*}{$R^{2}$} & \multirow[b]{2}{*}{$\Delta R^{2}$} \\
\hline & & & E & $\mathrm{T}$ & $\mathrm{L}$ & A & & & & & & $\begin{array}{c}a_{1} \\
(b 1+b 2)\end{array}$ & $\begin{array}{c}a_{2} \\
(b 3+b 4+b 5)\end{array}$ & $\begin{array}{c}a_{3} \\
(b 1+b 2) \\
\end{array}$ & $\begin{array}{c}a_{4} \\
\text { (b3+b4+b5) }\end{array}$ & & \\
\hline \multirow{5}{*}{$\begin{array}{c}\text { Job } \\
\text { Satisfaction }\end{array}$} & Job Complexity & $3.367^{* *}$ & -0.026 & 0.001 & $0.131^{* *}$ & 0.005 & 0.025 & 0.346 ** & 0.001 & -0.059 & $-0.080 *$ & $0.371 * *$ & $-0.138 *$ & $-0.321 *$ & -0.020 & $0.124 * *$ & $0.055^{* *}$ \\
\hline & Information Processing & $3.362 * *$ & -0.026 & 0.003 & 0.120 ** & 0.005 & 0.137 & $0.168 *$ & -0.033 & -0.069 & 0.026 & $0.305 * *$ & -0.076 & -0.031 & 0.062 & $0.099 * *$ & 0.030 ** \\
\hline & Problem Solving & $3.322 * *$ & -0.021 & 0.003 & 0.131 ** & 0.005 & 0.113 & 0.080 & 0.044 & -0.123 * & 0.040 & $0.193 *$ & -0.039 & 0.033 & 0.207 & $0.092 * *$ & $0.023 * *$ \\
\hline & Skill Variety & $3.407 * *$ & -0.031 & 0.002 & $0.113^{* *}$ & 0.005 & 0.136 & $0.120+$ & -0.030 & -0.006 & 0.003 & $0.256^{* *}$ & -0.033 & 0.016 & -0.021 & $0.099 * *$ & 0.030 ** \\
\hline & Specialization & 3.460 ** & -0.030 & 0.002 & $0.117^{* *}$ & 0.005 & 0.055 & 0.218 ** & 0.030 & $-0.094+$ & -0.011 & $0.273 * *$ & -0.075 & $-0.163+$ & 0.113 & 0.106 ** & $0.037^{* *}$ \\
\hline \multirow{5}{*}{$\begin{array}{c}\text { Job } \\
\text { Performance }\end{array}$} & Job Complexity & $3.606^{* *}$ & -0.002 & 0.001 & $0.061 *$ & 0.003 & 0.008 & $0.181 * *$ & 0.031 & -0.022 & 0.001 & $0.189 * *$ & 0.010 & $-0.173 * *$ & $0.054+$ & $0.145^{* *}$ & $0.079 * *$ \\
\hline & Information Processing & $3.631 * *$ & -0.008 & 0.003 & 0.036 & 0.003 & $0.151 *$ & 0.154 ** & 0.017 & $-0.075 *$ & 0.030 & $0.305 * *$ & -0.028 & -0.003 & 0.122 & $0.152 * *$ & $0.087 * *$ \\
\hline & Problem Solving & 3.616 ** & -0.003 & 0.003 & 0.050 * & 0.004 & $0.115 *$ & $0.058+$ & 0.023 & -0.040 & $0.052 * *$ & $0.173 * *$ & 0.035 & 0.057 & $0.115+$ & 0.146 ** & $0.081 * *$ \\
\hline & Skill Variety & $3.689 * *$ & -0.009 & 0.001 & 0.032 & 0.004 & $0.095+$ & -0.003 & -0.022 & $0.074+$ & $0.052 *$ & $0.092+$ & $0.104 * *$ & 0.098 & -0.044 & $0.196^{* *}$ & 0.131 ** \\
\hline & Specialization & 3.751 ** & -0.009 & 0.003 & $0.042+$ & 0.002 & 0.100 * & 0.106 ** & 0.008 & -0.037 & 0.026 & 0.206 ** & -0.003 & -0.006 & 0.071 & 0.140 ** & 0.075 ** \\
\hline
\end{tabular}

$N=531 .+p<0.10 .{ }^{*} p<0.05 . * * p<.01 . \mathrm{E}=$ Education, $\mathrm{T}=$ Organizational tenure, $\mathrm{L}=$ Occupational level, $\mathrm{A}=\mathrm{Age} . \mathrm{KC}=$ Knowledge characteristic, IMP $=$ Importance of knowledge characteristic. The column $\Delta R^{2}$ corresponds to the difference test for the $R^{2}$ values of the model with controls and the full model. 


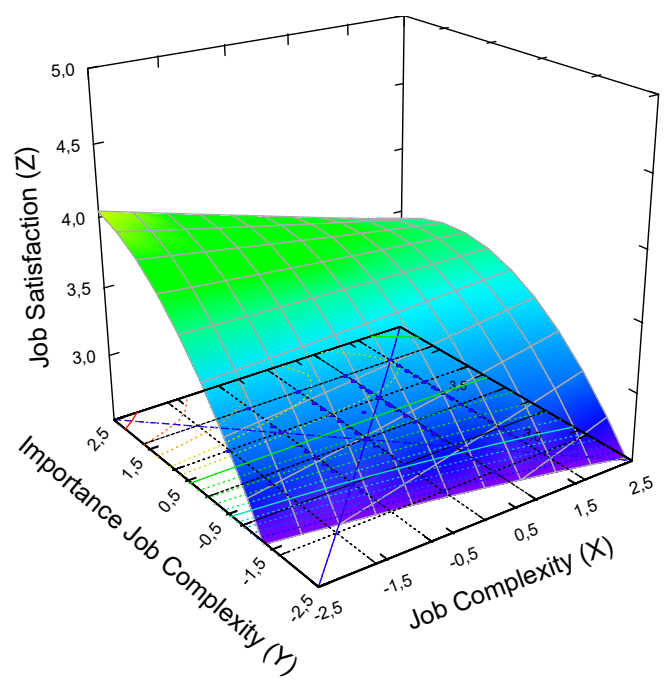

(a)

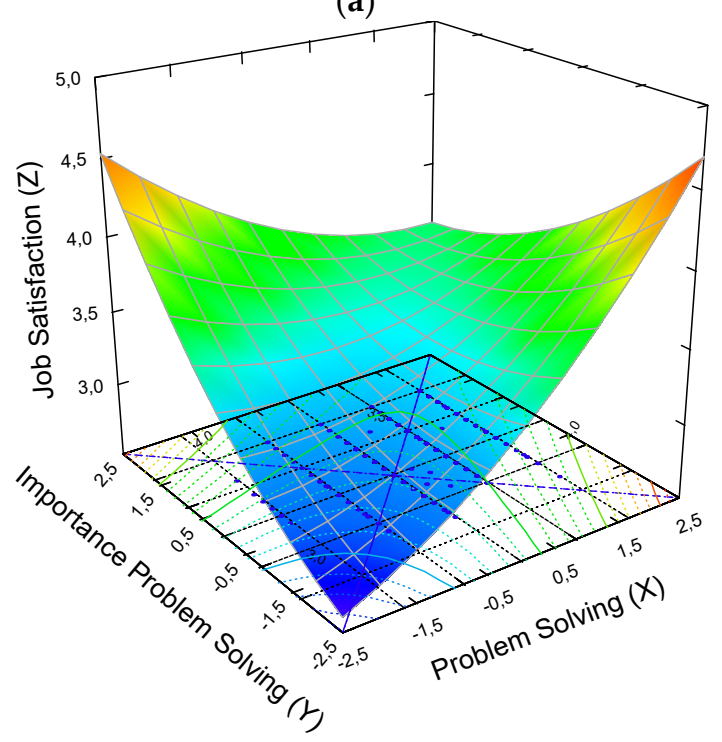

(c)

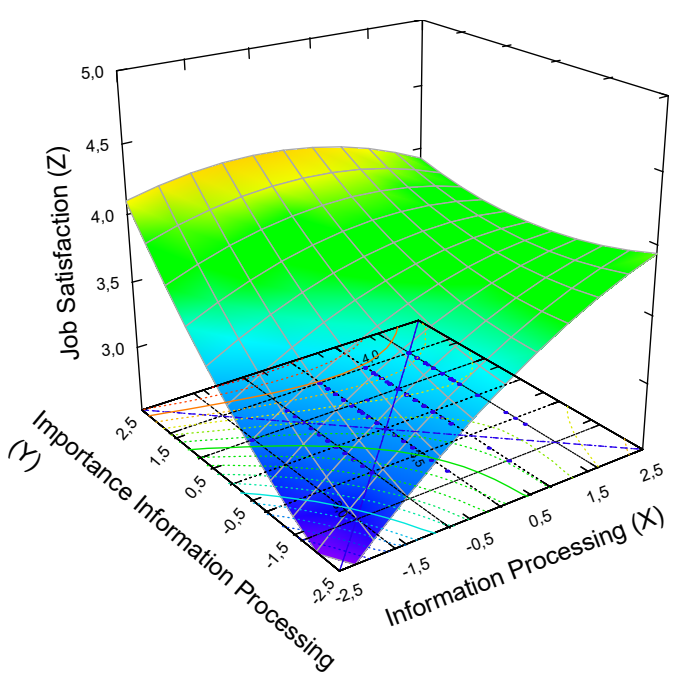

(b)

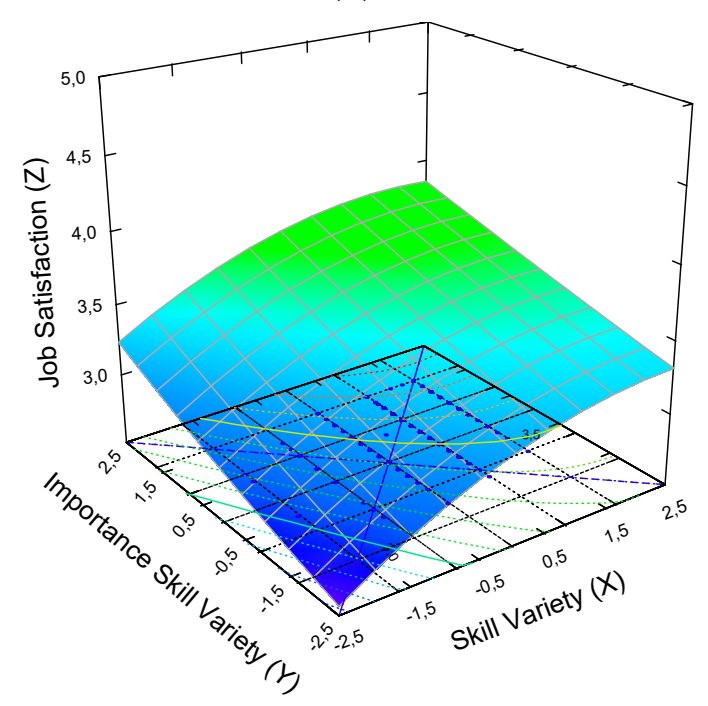

(d)

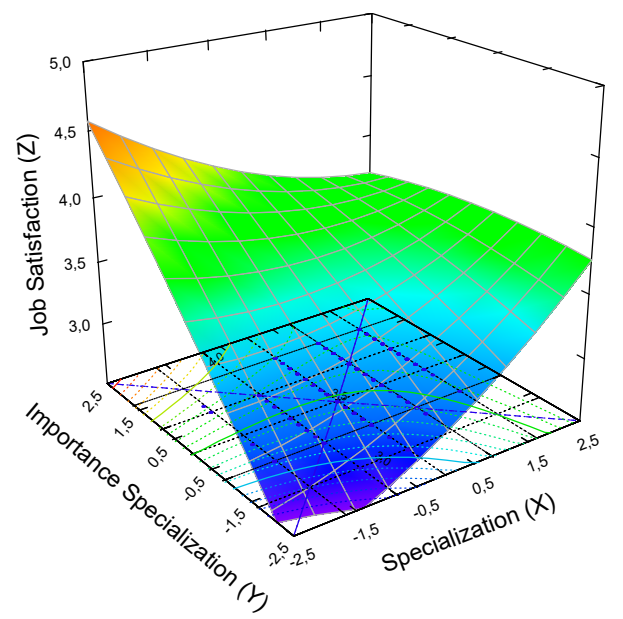

(e)

Figure 2. Congruence effect between knowledge characteristics and importance of knowledge characteristics on job satisfaction for: (a) job complexity, (b) information processing, (c) problem solving, (d) skill variety, and (e) specialization. 


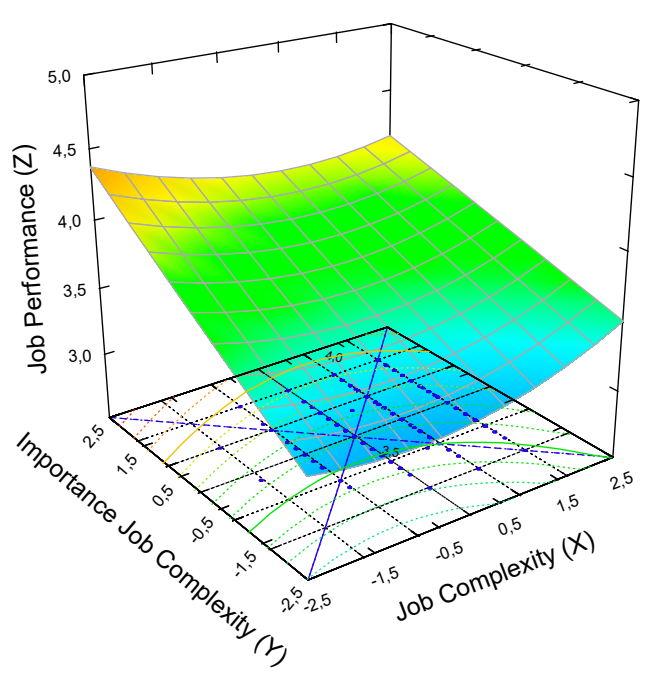

(a)

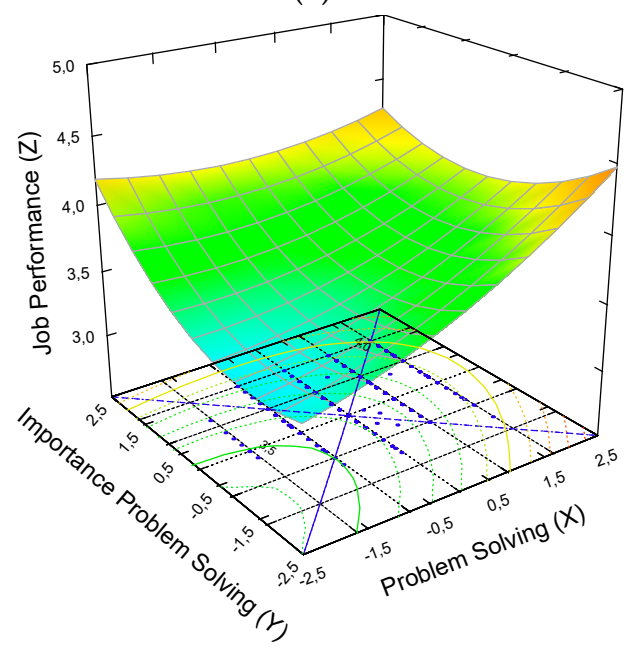

(c)

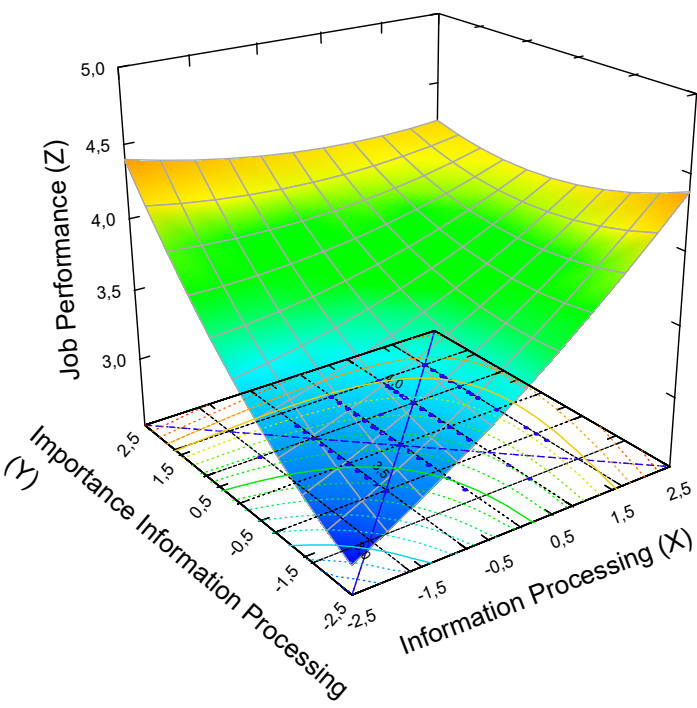

(b)

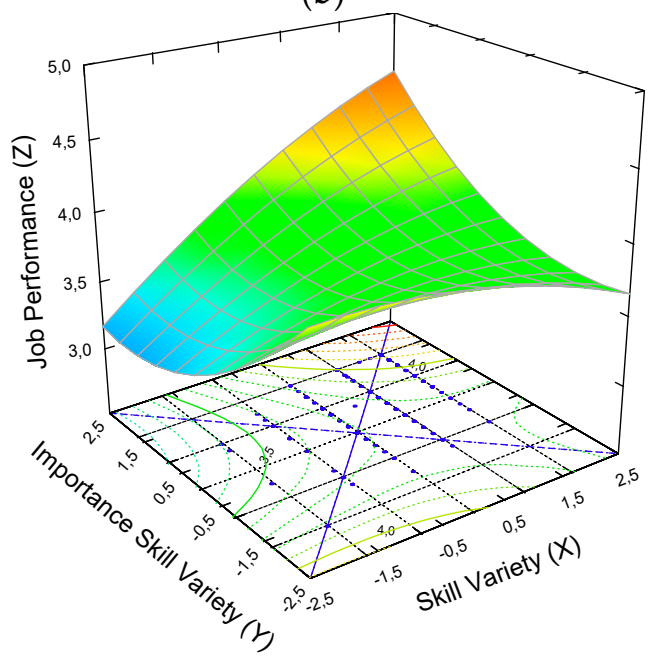

(d)

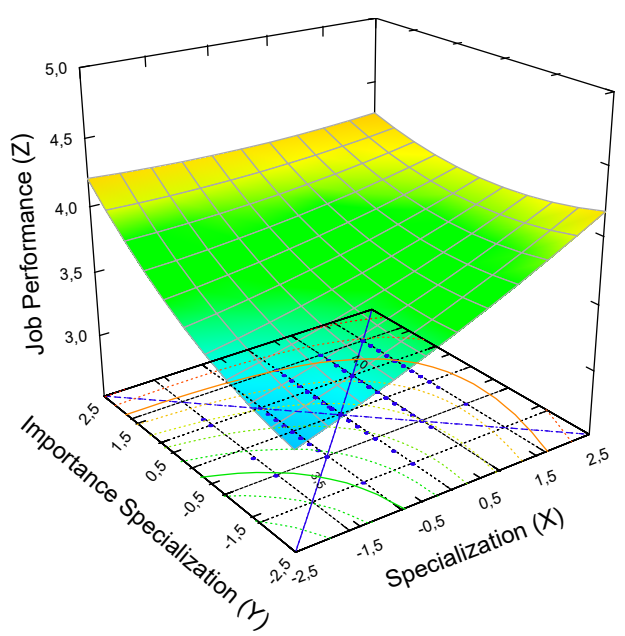

(e)

Figure 3. Congruence effect between knowledge characteristics and importance of knowledge characteristics on job performance for: (a) job complexity, (b) information processing, (c) problem solving, (d) skill variety, and (e) specialization. 
In relation to the incongruence line (Table 2, $\mathrm{KC}=-\mathrm{IMP}$ line), we found two significant results: for job complexity, the slope and curvature of the incongruence line present significant values, showing that job performance was high when job complexity was low, but its level of importance was still high (Figure 3a). In addition, for problem solving, the curvature of the incongruence line was also significant $(p<0.10)$, showing that there is a concave surface across this line. However, because the slope was non-significant, there is no clear interpretation for job performance.

Results for $\mathrm{H} 2$ are presented in Tables 3 and 4. From a simple mediation analysis conducted using ordinary least squares path analysis, knowledge characteristics' congruence indirectly influenced job satisfaction and job performance through its effect on work engagement. As Table 3 shows, workers with higher levels of fit between knowledge characteristics and importance had higher levels of work engagement (mean size for fit $\rightarrow$ work engagement $=1.345$ ), and workers with higher work engagement had higher job satisfaction (mean size work engagement $\rightarrow$ job satisfaction $=0.618$ ). A bias-corrected bootstrap confidence interval for the indirect effect, based on 10000 bootstrap samples, was entirely above zero (mean size knowledge characteristics $\rightarrow$ work engagement $\rightarrow$ job satisfaction $=0.832$ ). There was also evidence that knowledge characteristics' fit influences job satisfaction, regardless of its effect on work engagement (mean size FIT $\rightarrow$ job satisfaction $=0.357$ ). Overall, these results fully support H2a (for all knowledge characteristics).

In addition, as Table 4 reveals, workers with higher levels of fit between knowledge characteristics and IWC also had higher levels of work engagement (mean size for FIT $\rightarrow$ work engagement $=1.189$ ), and workers with higher work engagement had higher job performance (mean size work engagement $\rightarrow$ job performance $=0.263$ ). A bias-corrected bootstrap confidence interval for the indirect effect, based on 10000 bootstrap samples, was entirely above zero (mean size knowledge characteristics $\rightarrow$ work engagement $\rightarrow$ job performance $=0.313$ ). There was also evidence that knowledge characteristics' fit influenced job performance, regardless of its effect on work engagement (mean size FIT $\rightarrow$ job performance $=0.804$ ). Overall, these results fully support $\mathrm{H} 2 \mathrm{~b}$ (for all knowledge characteristics). 
Table 3. Ordinary least squares regression model coefficients for job satisfaction.

\begin{tabular}{|c|c|c|c|c|c|}
\hline Knowledge Characteristic & $\begin{array}{l}\text { Step } 1 \\
\text { FIT } \rightarrow \text { WE } \\
\text { Size (SE) }\end{array}$ & $\begin{array}{c}\text { Step } 2 \\
\text { WE } \rightarrow \text { JS } \\
\text { Size }(S E)\end{array}$ & $\begin{array}{l}\text { Direct Effect } \\
\text { FIT } \rightarrow \text { JS } \\
\text { Size (SE) }\end{array}$ & $\begin{array}{c}\text { Indirect Effect } \\
\text { KC } \rightarrow \text { WE } \rightarrow \text { JS } \\
\text { Size (Boot SE) LLCI, ULCI }\end{array}$ & $\begin{array}{c}\text { Total Effect } \\
\text { Direct }+ \text { Indirect } \rightarrow \text { JS } \\
\text { Size (SE) }\end{array}$ \\
\hline 1. Job complexity & $1.154^{* * *}(0.192)$ & $0.612 * * *(0.030)$ & $0.389^{* *}(0.136)$ & $0.706(0.150) 0.428,1.008$ & $1.094^{* * *}(0.176)$ \\
\hline 2. Information processing & $1.655^{* * *}(0.247)$ & $0.623^{* * *}(0.030)$ & $0.208(0.180)$ & 1.032 (0.191) 0.672, 1.439 & $1.239^{* * *}(0.231)$ \\
\hline 3. Problem solving & $1.044^{* * *}(0.298)$ & $0.624^{* * *}(0.030)$ & $0.443 *(0.204)$ & $0.651(0.250) 0.170,1.152$ & $1.094^{* * *}(0.274)$ \\
\hline 4. Skill variety & $1.469^{* * *}(0.242)$ & $0.619 * * *(0.030)$ & $0.314(0.173)$ & $0.910(0.223) 0.508,1.395$ & $1.224^{* * *}(0.224)$ \\
\hline 5. Specialization & $1.405^{* * *}(0.224)$ & $0.612 * * *(0.030)$ & $0.431 * *(0.160)$ & $0.860(0.200) 0.475,1.263$ & $1.291^{* * *}(0.207)$ \\
\hline
\end{tabular}

KC: Knowledge characteristic, WE: Work engagement, JS: Job satisfaction. LLCI: Lower level confidence interval (95\%), ULCI: Upper level confidence interval (95\%), SE: Standard error. All control variables are included as covariates in the block variables. $n=531 .{ }^{*} p<0.05 .{ }^{* *} p<0.01{ }^{* * *} p<0.001$.

Table 4. Ordinary least squares regression model coefficients for job performance.

\begin{tabular}{|c|c|c|c|c|c|}
\hline Knowledge Characteristic & $\begin{array}{c}\text { Step } 1 \\
\text { FIT } \rightarrow \text { WE } \\
\text { Size (SE) }\end{array}$ & $\begin{array}{l}\text { Step } 2 \\
\text { WE } \rightarrow \text { JP } \\
\text { Size }(S E)\end{array}$ & $\begin{array}{l}\text { Direct Effect } \\
\text { FIT } \rightarrow \text { JP } \\
\text { Size (SE) }\end{array}$ & $\begin{array}{c}\text { Indirect Effect } \\
\text { KC } \rightarrow \text { WE } \rightarrow \text { JP } \\
\text { Size }(\text { Boot SE) LLCI, ULCI }\end{array}$ & $\begin{array}{c}\text { Total Effect } \\
\text { Direct }+ \text { Indirect } \rightarrow \text { JP } \\
\text { Size (SE) }\end{array}$ \\
\hline 1. Job complexity & $1.288^{* * *}(0.234)$ & $0.266^{* * *}(0.023)$ & $0.826^{* * *}(0.128)$ & $0.342(0.080) 0.190,0.503$ & $1.168^{* * *}(0.139)$ \\
\hline 2. Information processing & $1.298^{* * *}(0.218)$ & $0.266^{* * *}(0.023)$ & $0.725^{* * *}(0.121)$ & 0.345 (0.076) $0.207,0.498$ & $1.070^{* * *}(0.131)$ \\
\hline 3. Problem solving & $1.031^{* * *}(0.228)$ & $0.271^{* * *}(0.023)$ & $0.828^{* * *}(0.122)$ & 0.279 (0.079) $0.130,0.441$ & $1.107^{* * *}(0.134)$ \\
\hline 4. Skill variety & $0.987^{* * *}(0.173)$ & $0.252^{* * *}(0.023)$ & $0.826^{* * *}(0.092)$ & $0.249(0.054) 0.148,0.359$ & $1.074^{* * *}(0.099)$ \\
\hline 5. Specialization & $1.341^{* * *}(0.223)$ & $0.262 * * *(0.023)$ & $0.817^{* * *}(0.123)$ & $0.351(0.081) 0.203,0.518$ & $1.168^{* * *}(0.133)$ \\
\hline
\end{tabular}

KC: Knowledge characteristic, WE: Work engagement, JS: Job satisfaction. LLCI: Lower level confidence interval (95\%), ULCI: Upper level confidence interval (95\%), SE: Standard error. All control variables are included as covariates in the block variables. $n=531$. $^{*} p<0.05$. ${ }^{* *} p<0.01{ }^{* * *} p<0.001$. 


\section{Discussion}

The aim of this study was to provide empirical evidence from a sample of workers about the influence of harmony between the presence of knowledge characteristics and the importance given to these characteristics on job satisfaction and job performance. In addition, we tested the moderating role of work engagement in this relationship. Our hypotheses state that the congruence between knowledge characteristics and importance is positively related to job satisfaction and job performance, and that work engagement partially mediates the relationship between knowledge characteristics' congruence (i.e., job complexity, information processing, problem solving, skill variety, specialization) and both job satisfaction and job performance. Mediation analyses for each knowledge characteristic-work engagement-job performance path fully confirmed partial mediation for all the knowledge characteristics. These results offer several theoretical and practical implications.

\subsection{Theoretical Implications}

First, this study contributes to the HRM literature by expanding the body of knowledge related to job performance, highlighting "high value performance" associated with congruence between the contextual demands of the job (knowledge characteristics) and personal preferences of workers (Importance), as well as higher work engagement and job satisfaction. In particular, the congruence between knowledge characteristics and importance is central to understanding importance as a value. The level of importance can be interpreted as a dynamic resource that can vary in accordance with the perception, attitudes, and other personal attributes of the worker.

Second, this study contributes to the HRM literature by expanding the body of knowledge on the effect of work engagement on job performance and job satisfaction. The results of the current study deepen our understanding of the mechanism that connects knowledge characteristics with job performance, by showing that work engagement is a key variable in understanding the effect of knowledge characteristics on job performance and job satisfaction; indeed, traditional job enrichment per se is not sufficient to explain job performance or job satisfaction. As in all comparisons, knowledge characteristics' fit was found to indirectly affect job performance and job satisfaction through its effect on work engagement (i.e., workers with higher knowledge characteristics' fit are more engaged with their jobs, which, in turn, influences job satisfaction and job performance). These results can be explained using the personal salience model [20], which proposes that if something is viewed as personally salient (e.g., the worker attributes personal importance to autonomy), it is more highly desired. Workers who assign more importance to certain knowledge characteristics are more inclined to pay more attention to the information pertaining to these knowledge characteristics, and, as a result, the related outcomes will be of higher quality (i.e., higher job satisfaction and job performance). This argument is particularly relevant in the case of knowledge characteristics because, for example, jobs with high levels of information-processing, problem-solving, skill variety, and specialization require employees to be more careful about job demands; in such cases, workers who assign more importance to these characteristics are more likely to perform the job with greater care and achieve better job performance.

Third, we found little evidence of the influence of controls on the initial congruence tests because age, organizational tenure, and education had no significant impact on the model. However, the occupational level was a significant factor in job satisfaction for all the knowledge characteristics, and in job performance for four knowledge characteristics. Thus, as workers rise in the organizational hierarchy, they tend to give more importance to knowledge characteristics' fit, as in our sample. The higher up they are in the hierarchy, the more responsibilities workers will have, and their positions will be more complex and require more problem solving.

Finally, using Person-Job fit theory, we found strong evidence for the sustainability of psychological resources because harmony between the worker's results (satisfaction) and the organization's results (performance) is possible and leads the worker to a state of engagement. Harmony between the 
demands of the environment and the demands of the worker is also possible, and when harmony is achieved, the wellbeing of individuals increases.

\subsection{Managerial Implications}

The findings of this study have important HRM implications, especially with regard to retention, work design, and selection, but also in terms of prevention. In the case of work design, human resources practitioners should consider (a) a larger number of knowledge characteristics that include a broad range of knowledge creation and processing and (b) worker preferences about these knowledge characteristics. More knowledge characteristics need to be considered, especially those that reflect the current labor market, which is based on a knowledge economy. In addition, we showed that when creating an enriched job environment featuring high-level knowledge characteristics, organizations should consider the similarity between the aforementioned knowledge characteristics and worker preferences. Such considerations align with Person-Job fit [50], where higher work outcomes are expected when worker and job characteristics are congruent. These results are consistent with current job design trends, where job performance is guided not only by the work context, but also by worker preferences and expectations. This resembles work design approaches that incorporate job crafting and idiosyncratic deals, where employers consider the unique values and preferences of workers [14].

Another managerial implication is related to the worker selection process. Our results present an opportunity to explore the construction of "congruence profiles," which may help managers to align their human resources with workplace demands and needs. These congruence profiles are especially relevant for job positions where workers have a high load of problem solving or other knowledge characteristics because they are important for maintaining congruence in the key knowledge characteristics of each job. Importance may be used as a key indicator during the selection process because the likelihood of a successful selection process can be increased if there is good congruence between the key knowledge characteristics of a job and the importance assigned to these knowledge characteristics by the job candidate. Additionally, a new worker will feel more confident, more prepared to cope with stress, and better suited to a job that matches his or her preferences, which in turn will improve job satisfaction.

In addition, improving these processes (work design and selection) would be an effective strategy to improve worker retention because talented workers who perform a challenging job that is congruent with their interests will have higher internal motivation, which in turn will be related to higher job satisfaction and job performance.

Finally, our results relating harmony between knowledge characteristics and their importance and job satisfaction can also be interpreted as a positive outcome leading to primary prevention of negative reactions in workers [12]. When the characteristics and demands of the job meet the workers' expectations, their well-being is expected because they are in harmony with the environment. When there is a balance between the individual and the environment, sustainability is a natural outcome. Therefore, in order to obtain a psychologically harmonious organization that meets the need for productivity and satisfaction, the expectations and capacities of the worker should match the expectations and demands of the job, leading to a state of engagement, which in turn improves both satisfaction and performance. Considering this primary prevention perspective, increasing the harmonization between workers and their environment will build strengths that can protect and sustain the environment-not just psychological strengths, but also environmental, economic, and social, because the first step in obtaining a sustainable organization is achieving an engaged and productive workforce.

\subsection{Limitations and Suggestions for Future Research}

Although this study produced some interesting results, it has three major limitations. The first is the sampling method employed. Although we collected the sample in two different moments and most of the ISIC occupational groups were considered, some groups were underrepresented (e.g., water 
supply and arts, entertainment, and recreation). In addition, it is important to consider that half of Colombia's labor market is informal, and this study's conclusions may apply only to workers employed in the formal labor market. Future research should consider the structure of work characteristics in this population (e.g., how problem solving is viewed by street vendors, or how knowledge characteristics are experienced by self-employed workers in small workshops or self-owned convenience stores).

The second limitation is the potential presence of some level of common method bias. In our study, we used two methods to control it (i.e., a procedural and a statistical method). We used a procedural method, in which the temporal separation between the predictor and criterion variables contributes to reducing the potential influence of common method bias [51], and a statistical method, using a CLF test, whose results indicated that variance due to common method bias was not a problem. The self-evaluation of performance could lead to this bias, which means that the results should be interpreted with caution. This finding is consistent with those from previous studies on common method variance, which conclude that even if common method bias is present, it does not always significantly affect the results or conclusions based on the data [52,53]. Future research should explore causation in the relationship between knowledge characteristics, job satisfaction, and job performance.

Third, because the current study assessed only knowledge characteristics, future studies should expand the number of outcome variables considered and, thus, confirm our results, particularly the retention rate, because our hypotheses indicate that workers who have a congruent job with high work engagement and job satisfaction will stay in their organizations longer than those who do not. These findings could focus on other behavioral and attitudinal variables, such as organizational commitment, turnover, absenteeism, and objective performance. Considering the results obtained in the current study, it is important to explore the different effects of the congruence of knowledge characteristics on various attitudinal and behavioral outcomes, depending on the personal needs of the workers (e.g., their job expectations based on their family composition), in order to identify certain job profiles (both for congruence and incongruence) that will be related to positive and negative outcomes. Additionally, it is important to consider the specific characteristics of occupational groups because the relationship between congruence and job performance is not the same for all of them, and so congruence profiles should consider a job's hierarchical position and roles.

Finally, our study had a cross-sectional design that took into account a certain moment in time. As we have reported, harmonization can bring wellbeing to both the workers (i.e., engagement and satisfaction) and the organization (i.e., performance). A final future research proposal is related to the stability of this gain in terms of sustainability. Sustainable development can be achieved by fostering harmonization. Using longitudinal research models, we can trace the sustainable development of organizations that focus on the fit (i.e., harmonization) between the preferences of the worker and those of the organization. This longitudinal design can also shed light on the more information about how Person-Job fit is an antecedent of work engagement and not vice versa.

\section{Conclusions}

Changes in work configurations, with more complex and dynamic jobs, have led HRM departments to increase their efforts to attract and retain workers, taking into account not only traditional systems of direct compensation, but also the job itself as an internal motivator that considers the values and interests of workers. Our results highlight the key role of harmony between the level of knowledge characteristics and the level of importance given to such characteristics, which, in turn, improves work engagement. It is important for workers to value their positions and their tasks-not only to obtain greater job satisfaction, but also to achieve better job performance.

Author Contributions: Conceptualization, J.A.B., A.C. and J.M.P.; methodology, J.A.B., A.C. and J.M.P.; software, J.A.B.; validation, J.A.B.; formal analysis, J.A.B.; investigation, J.A.B., A.C. and J.M.P.; resources, J.A.B.; data curation, J.A.B.; writing-original draft preparation, J.A.B.; writing-review and editing, J.A.B., A.C. and J.M.P.; visualization, J.A.B.; supervision, A.C. and J.M.P.; project administration, J.M.P.; funding acquisition, J.A.B. and J.M.P. All authors have read and agreed to the published version of the manuscript. 
Funding: This research was funded by Pontificia Universidad Javeriana, grant number 7853; MINECO/FEDER under Grant PSI2015-6I4862-R; and the research groups of excellence GV. PROMETEO 2016/138.

Conflicts of Interest: The authors declare no conflict of interest.

\section{References}

1. O'Boyle, E.; Kroska, S. Star Performers. In The Oxford Handbook of Talent Management; Collings, D.G., Mellahi, K., Cascio, W.F., Eds.; Oxford University Press: Oxford, UK, 2017; Volume 1.

2. Call, M.L.; Nyberg, A.J.; Thatcher, S.M.B. Stargazing: An integrative conceptual review, theoretical reconciliation, and extension for star employee research. J. Appl. Psychol. 2015, 100, 623-640. [CrossRef] [PubMed]

3. Cappelli, P.; Keller, J. Talent Management: Conceptual Approaches and Practical Challenges. Annu. Rev. Organ. Psychol. Organ. Behav. 2014, 1, 305-331. [CrossRef]

4. Di Fabio, A.; Rosen, M.A. Opening the Black Box of Psychological Processes in the Science of Sustainable Development: A New Frontier. Eur. J. Sustain. Dev. Res. 2018, 2, 2-6. [CrossRef]

5. Chambers, E.G.; Foulon, M.; Handfield-Jones, H.; Hankin, S.M.; Michaels, E.G. The War for Talent. McKinsey Q. 1998, 44-58.

6. Salanova, M.; Schaufeli, W.B.; Xanthopoulou, D.; Bakker, A.B. The gain spiral of resources and work engagement: Sustaining a positive worklife. In Work Engagement: A Handbook of Essential Theory and Research; Bakker, A.B., Leiter, M.P., Eds.; Psychology Press: New York, NY, USA, 2010; pp. 118-131.

7. Xanthopoulou, D.; Bakker, A.B.; Heuven, E.; Demerouti, E.; Schaufeli, W.B. Working in the sky: A diary study on work engagement among flight attendants. J. Occup. Health Psychol. 2008, 13, 345-356. [CrossRef]

8. Christian, M.S.; Garza, A.S.; Slaughter, J.E. Work engagement: A quantitative review and test of its relations with task and contextual performance. Pers. Psychol. 2011, 64, 89-136. [CrossRef]

9. Peiró, J.M.; Ayala, Y.; Tordera, N.; Lorente, L. Bienestar Sostenible en el Trabajo: Revisión y Reformulación. Pap. Del Psicólogo 2014, 35, 5-14.

10. Peiró, J.; Kozusznik, M.; Rodríguez-Molina, I.; Tordera, N. The Happy-Productive Worker Model and Beyond: Patterns of Wellbeing and Performance at Work. Int. J. Environ. Res. Public Health 2019, 16, 479. [CrossRef]

11. Kożusznik, M.W.; Peiró, J.M.; Soriano, A. Daily eudaimonic well-being as a predictor of daily performance: A dynamic lens. PLoS ONE 2019, 14. [CrossRef]

12. Di Fabio, A.; Tsuda, A. The psychology of Harmony and Harmonization: Advancing the perspectives for the psychology of sustainability and sustainable development. Sustainability 2018, 10, 4726. [CrossRef]

13. Peiró, J.M.; Bayona, J.A.; Caballer, A.; Di Fabio, A. Importance of work characteristics affects job performance: The mediating role of individual dispositions on the work design-performance relationships. Pers. Individ. Differ. 2020, 157. [CrossRef]

14. Grant, A.M.; Parker, S.K. Redesigning Work Design Theories: The Rise of Relational and Proactive Perspectives. Acad. Manag. Ann. 2009, 3, 317-375. [CrossRef]

15. Grant, A.M.; Fried, Y.; Juillerat, T. Work matters: Job design in classic and contemporary perspectives. In $A P A$ Handbook of Industrial and Organizational Psychology, Vol 1: Building and Developing the Organization; Zedeck, S., Ed.; American Psychological Association: Washington, DC, USA, 2010; pp. 417-453.

16. Morgeson, F.P.; Humphrey, S.E. The Work Design Questionnaire (WDQ): Developing and validating a comprehensive measure for assessing job design and the nature of work. J. Appl. Psychol. 2006, 91, 1321-1339. [CrossRef]

17. Humphrey, S.E.; Nahrgang, J.D.; Morgeson, F.P. Integrating motivational, social, and contextual work design features: A meta-analytic summary and theoretical extension of the work design literature. J. Appl. Psychol. 2007, 92, 1332-1356. [CrossRef] [PubMed]

18. Lievens, I.; Vlerick, P. Transformational leadership and safety performance among nurses: The mediating role of knowledge-related job characteristics. J. Adv. Nurs. 2014, 70, 651-661. [CrossRef]

19. Wei, L. Effects of positive mood and job complexity on employee creativity and performance. Soc. Behav. Pers. 2016, 44, 865-880.

20. Warr, P. Work, Happiness, and Unhappiness; Routledge: New York, NY, USA, 2007. 
21. Edwards, J.R.; Cable, D.M.; Williamson, I.O.; Lambert, L.S.; Shipp, A.J. The phenomenology of fit: Linking the person and environment to the subjective experience of person-environment fit. J. Appl. Psychol. 2006, 91, 802-827. [CrossRef]

22. Campbell, J.P.; Wiernik, B.M. The Modeling and Assessment of Work Performance. Annu. Rev. Organ. Psychol. Organ. Behav. 2015, 2, 47-74. [CrossRef]

23. Edwards, J.R.; Shipp, A.J. The Relationship Between Person-Environment Fit and Outcomes: An Integrative Theoretical Framework. In Perspectives on Organizational Fit; Ostroff, C., Judge, T.A., Eds.; Jossey-Bass: San Francisco, CA, USA, 2007; pp. 209-258.

24. Ostroff, C.; Schulte, M. Multiple perspectives of fit in organizations across levels of analysis. In Perspectives on Organizational Fit; Ostroff, C., Judge, T.A., Eds.; Psychology Press: New York, NY, USA, 2007; pp. 3-69.

25. Hoffman, B.J.; Woehr, D.J. A quantitative review of the relationship between person-organization fit and behavioral outcomes. J. Vocat. Behav. 2006, 68, 389-399. [CrossRef]

26. Kristof-Brown, A.L.; Zimmerman, R.D.; Johnson, E.C. Consequences of Individuals' Fit at Work: A Meta-analysis of Person-Job, Person-organization, Person-group, and Person-supervisor Fit. Pers. Psychol. 2005, 58, 281-342. [CrossRef]

27. Bakker, A.B.; Demerouti, E.; Sanz-Vergel, A.I. Burnout and Work Engagement: The JD-R Approach. Annu. Rev. Organ. Psychol. Organ. Behav. 2014, 1, 389-411. [CrossRef]

28. Harter, J.K.; Schmidt, F.L.; Agrawal, S.; Plowman, S.K.; Blue, A. The Relationship Between Engagement at Work and Organizational Outcomes 2016 Q12 ${ }^{\circledR}$ Meta-Analysis; Gallup New Directions Consulting: Washington, DC, USA, 2016.

29. Bakker, A.B.; Albrecht, S.L.; Leiter, M.P. Work engagement: Further reflections on the state of play. Eur. J. Work Organ. Psychol. 2011, 20, 74-88. [CrossRef]

30. Schaufeli, W.B.; Salanova, M.; Bakker, A.B.; Gonzales-Roma, V. The Measurement of Engagement and Burnout: A two sample confirmatory Factor Analytic Approach. J. Happiness Stud. 2002, 3, 71-92. [CrossRef]

31. Harter, J.K.; Schmidt, F.L.; Hayes, T.L. Business-unit-level relationship between employee satisfaction, employee engagement, and business outcomes: A meta-analysis. J. Appl. Psychol. 2002, 87, 268-279. [CrossRef] [PubMed]

32. Schaufeli, W.B.; Bakker, A.B. Defining and measuring work engagement: Bringing clarity to the concept. In Work Engagement: A Handbook of Essential Theory and Research; Bakker, A.B., Leiter, M.P., Eds.; Psychology Press: New York, NY, USA, 2010; pp. 10-24.

33. Kahn, W.A. Psychological Conditions of Personal Engagement and Disengagement At Work. Acad. Manag. J. 1990, 33, 692-724.

34. Rich, B.L.; Lepine, J.A.; Crawford, E.R. Job Engagement: Antecedents and Effects on Job Performance. Acad. Manag. J. 2010, 53, 617-635. [CrossRef]

35. Lorente, L.; Salanova, M.; Martínez, I.M.; Vera, M. How personal resources predict work engagement and self-rated performance among construction workers: A social cognitive perspective. Int. J. Psychol. 2014, 49, 200-207. [CrossRef]

36. Raymark, P.H.; Schmit, M.J.; Guion, R.M. Identifying Potentially Useful Personality Constructs for Employee Selection. Pers. Psychol. 1997, 50, 723-736. [CrossRef]

37. United Nations. International Standard Industrial Classification of All Economic Activities (ISIC), Rev.4; United Nations: New York, NY, USA, 2008.

38. Bayona, J.A.; Caballer, A.; Peiró, J.-M. The Work Design Questionnaire: Spanish version and validation. Rev. Psicol. Del Trab. y las Organ. 2015, 31, 187-200. [CrossRef]

39. Cable, D.M.; Edwards, J.R. Complementary and supplementary fit: A theoretical and empirical integration. J. Appl. Psychol. 2004, 89, 822-834. [CrossRef]

40. Schaufeli, W.B.; Bakker, A.B. UWES Utrecht Work Engagement Scale; UWES: Utrecht, The Netherlands, 2003.

41. Abramis, D.J. Relationship of Job Stressors to Job Performance: Linear or Inverted-U? Psychol. Rep. 1994, 75, 547-558. [CrossRef] [PubMed]

42. Sora Miana, B.; González-Morales, M.G.; Caballer, A.; Peiró, J.M. Consequences of Job Insecurity and the Moderator Role of Occupational Group. Span. J. Psychol. 2011, 14, 820-831. [CrossRef] [PubMed]

43. Price, J.L. Handbook of organizational measurement. Int. J. Manpow. 1997, 18, 305-558. [CrossRef]

44. Isaksson, K. Psychological Contracts across Employment Situations (PSYCONES); European Comission: Brussels, Belgium, 2007. 
45. Edwards, J.R. Alternatives to difference scores: Polynomial regression analysis and response surface methodology. In Measuring and Analyzing Behavior in Organizations: Advances in Measurement and Data Analysis; Drasgow, F., Schmitt, N.W., Eds.; Jossey-Bass: San Francisco, CA, USA, 2002; pp. 350-400.

46. Edwards, J.R.; Cable, D.M. The value of value congruence. J. Appl. Psychol. 2009, 94, 654-677. [CrossRef] [PubMed]

47. Hayes, A.F. Introduction to Mediation, Moderation, and Conditional Process Analysis: A Regression-Based Approach; The Guilford Press: New York, NY, USA, 2013.

48. Podsakoff, P.M.; MacKenzie, S.B.; Lee, J.-Y.; Podsakoff, N.P. Common method biases in behavioral research: A critical review of the literature and recommended remedies. J. Appl. Psychol. 2003, 88, 879-903. [CrossRef]

49. Gaskin, J.; Lim, J. CFA Tool. Amos Plugin. 2017. Available online: http://statwiki.kolobkreations.com/index. php?title=Main_Page (accessed on 17 March 2020).

50. Kristof-Brown, A.; Guay, R.P. Person-Environment fit. In APA Handbook of Industrial and Organizational Psychology, Vol 3: Maintaining, Expanding, and Contracting the Organization.; American Psychological Association: Washington, DC, USA, 2011; pp. 3-50.

51. Podsakoff, P.M.; MacKenzie, S.B.; Podsakoff, N.P. Sources of Method Bias in Social Science Research and Recommendations on How to Control It. Annu. Rev. Psychol. 2012, 63, 539-569. [CrossRef]

52. Crampton, S.M.; Wagner, J.A. Percept-percept inflation in microorganizational research: An investigation of prevalence and effect. J. Appl. Psychol. 1994, 79, 67-76. [CrossRef]

53. Doty, D.H.; Glick, W.H. Common Methods Bias: Does Common Methods Variance Really Bias Results? Organ. Res. Methods 1998, 1, 374-406. [CrossRef]

(C) 2020 by the authors. Licensee MDPI, Basel, Switzerland. This article is an open access article distributed under the terms and conditions of the Creative Commons Attribution (CC BY) license (http://creativecommons.org/licenses/by/4.0/). 